Revista Eletrônica de Direito Processual - REDP.

Rio de Janeiro. Ano 12. Volume 19. Número 2. Maio a Agosto de 2018

Periódico Quadrimestral da Pós-Graduação Stricto Sensu em Direito Processual da UERJ

Patrono: José Carlos Barbosa Moreira (in mem.). ISSN 1982-7636. pp. 149-172 www.redp.uerj.br

\title{
COERÊNCIA E SISTEMA JURÍDICO ${ }^{1}$
}

\section{COHERENCE AND LEGAL SYSTEM}

Juliano Heinen

Doutorando em Direito pela Universidade Federal do Rio Grande do Sul (UFRGS); Mestrado em Direito pela Universidade de Santa Cruz do Sul (UNISC). Professor de graduação em Direito (Faculdade IMED e da Fundação Escola Superior do Ministério Público (FMP) e de pósgraduação em Direito (Faculdade IMED, UNISINOS, UNIRITTER, Universidade de Caxias do Sul); professor nos cursos de extensão da Escola Superior da Magistratura Federal (ESMAFE), da Fundação Escola Superior do Ministério Público (FMP), da Fundação Escola Superior da Defensoria Pública do RS (FESDEP) e da Escola Superior de Advocacia Pública do RS (ESAPERGS). Procurador do Estado do Rio Grande do Sul. Porto Alegre/RS. E-mail: julianoheinen@hotmail.com

RESUMO: O presente trabalho aborda o tema da coerência no sistema jurídico a partir de vários planos metodológicos. Enfatiza-se o estudo das maneiras pelas quais se intenta conseguir coerência no âmbito do direito nacional, conferindo-se, pois, unidade e sistematicidade neste sentido. Destaca-se, por fim, a falta, no Brasil, de uma "teoria da coerência”, a começar pelos critérios aqui apresentados, por exemplo. Para tanto, utilizarse-á três perspectivas metodológicas, a perceber o objeto de estudo no plano analítico, no plano teleológico e no plano pragmático. Essa avaliação destaca a configuração do conceito multidimensional do termo, porque o seu significado acaba por deter elementos dogmáticos diferentes para cada ramo da legislação que se ocupa da coerência.

PALAVRAS-CHAVE: Coerência; sistema jurídico; ordenamento jurídico.

\footnotetext{
${ }^{1}$ Artigo recebido em 10/07/2017 e aprovado em 17/07/2018.
} 
Revista Eletrônica de Direito Processual - REDP.

Rio de Janeiro. Ano 12. Volume 19. Número 2. Maio a Agosto de 2018

Periódico Quadrimestral da Pós-Graduação Stricto Sensu em Direito Processual da UERJ

Patrono: José Carlos Barbosa Moreira (in mem.). ISSN 1982-7636. pp. 149-172

www.redp.uerj.br

ABSTRACT: The present paper addresses the issue of coherence in the legal system from several methodological planes. It emphasizes the study of the ways in which it is tried to achieve coherence in the scope of the national law, conferring, therefore, unity and systematicity in this sense. Finally, the lack in Brazil of a "theory of coherence", starting with the criteria presented here, for example. For this, three methodological perspectives will be used, to perceive the object of study in the analytical plane, in the teleological plane and in the pragmatic plane. This evaluation highlights the configuration of the many concept of the term, because its meaning ultimately has different dogmatic elements for each branch of legislation that deals with consistency.

KEY WORDS: Coherence; juridical system; Legal order.

SUMÁRIO: Introdução; 1 Coerência jurídica; 2 Coerência no plano analítico; 3 Coerência no plano horizontal; 4 Coerência no plano vertical; 5 Coerência do ordenamento jurídico perspectiva negativa; 6 Coerência da interpretação do ordenamento jurídico - perspectiva positiva; 7 Coerência na dimensão externa; 8 Coerência na dimensão interna; 9 Coerência no plano teleológico; 10 Coerência no plano pragmático; Considerações finais; Referências bibliográficas.

\section{Introdução}

Na Grécia antiga (período que vai desde o ano 1.100 a.C. até à dominação romana em 146 a.C.), os pensadores da época tinham grande preocupação em estudar o cosmos (kósmos). Para eles, cosmos era entendido como um "universo ordenado", onde se encontrava um local de "beleza" e de "harmonia". Seu oposto era o caos (Cháos), onde pairava a desordem, a qual levava à ruína - enfim, onde tudo era feio e sem harmonia. De modo que o estudo da natureza, por exemplo, levava o pensador a contemplar um todo ordenado, que poderia ir desde as estrelas aos átomos. O estudioso das ditas "ciências naturais" teria a tarefa de revelar ou de descrever este "todo".

Contudo, o direito não é um produto da natureza, mas sim, algo que foi criado pela racionalidade humana. Por isto, ele é um “cosmos fabricado", que não basta ser descrito, 
Revista Eletrônica de Direito Processual - REDP.

Rio de Janeiro. Ano 12. Volume 19. Número 2. Maio a Agosto de 2018

Periódico Quadrimestral da Pós-Graduação Stricto Sensu em Direito Processual da UERJ

Patrono: José Carlos Barbosa Moreira (in mem.). ISSN 1982-7636. pp. 149-172

www.redp.uerj.br

porque reclama uma análise de sua própria construção e de sua aplicação, de modo a fazer

sentido, ou seja, de modo ser reputado coerente. E será este o objeto central do presente ensaio.

Aliás, essa é uma das razões pelas quais o instituto da coerência é tema sensível no mundo contemporâneo. Reputa-se assunto constantemente revisitado pela doutrina, porque não se esgota. Nos dias de hoje, recebe ainda mais relevância, diante de tantas contingências. Não temos dúvida, portanto, de que o tema ora abordado deverá ser enfrentado novamente no curso dos tempos que seguirão, a ganhar a devida atualidade.

Vale dizer, então, que o presente trabalho analisará o fenômeno da coerência no cenário jurídico, e se proporá a perfazer uma compreensão analítica e pragmática da coerência, expondo as ferramentas jurídicas para sua maior operacionalidade. É certo que outros temas poderiam ser abordados, mas se optou por evidenciar mecanismos importantes e corriqueiramente vistos em ação no cotidiano da estrutura estatal.

Os motivos para a existência de um debate pulsante na temática escolhida são de difícil comprovação, e existem visto que a discussão científica sobre o tema não está acabada. Por isto, algumas constatações nos parecem inevitáveis: o mundo contemporâneo experimenta, em meio à fugacidade das coisas, uma insegurança abrupta em quase todos os tipos de relacionamentos humanas, entre outros fatores. E aqueles marcadamente jurídicos não ficaram à margem deste processo. A insegurança jurídica, causada por inúmeros fatores, é extremamente nefasta, pois causa contingência e desconfiança. Além disso, a pluralidade foi enaltecida na mesma medida em que ascendeu, no Brasil, a própria democracia.

Logo, a necessidade de o sistema jurídico ganhar maior coerência ficou evidente. Cada vez mais a insegurança social perpassa o mundo moderno. A sociedade contemporânea experimenta grande mudança por meio dos fenômenos de massificação que vêm ocorrendo como corolário da adaptação da lógica das relações econômicas fugazes à vida social. A complexidade das conexões humanas passa a ser cada vez maior. Neste contexto, cresce a importância do direito como ferramenta de regulamentação da coletividade, conferindo, aos seus membros, certa carga de previsibilidade, de estabilidade e de unidade do direito. Esta consequência ofertada pela mencionada regulação deveria diminuir a contingência. 
Revista Eletrônica de Direito Processual - REDP.

Rio de Janeiro. Ano 12. Volume 19. Número 2. Maio a Agosto de 2018

Periódico Quadrimestral da Pós-Graduação Stricto Sensu em Direito Processual da UERJ

Patrono: José Carlos Barbosa Moreira (in mem.). ISSN 1982-7636. pp. 149-172

www.redp.uerj.br

Todavia, não raras vezes, a mesma regulação pode trazer à tona uma insegurança

ainda maior, especialmente quando as regras são feitas de atecnicamente, ou, o que é mais grave, quando se percebem toda sorte de contradições e antinomias. De outro lado, as relações sociais estão justamente a reclamar uma ordenação precisa. Eis um dos grandes desafios do direito: evitar o descrédito na sua própria normatividade. Sendo assim, o sistema jurídico vem se esforçando em ofertar mecanismos para se implementar coerência, a fim de minimizar a contingência e o risco que a ausência de confiança causa nas relações. Esta busca por mecanismos que criem maior previsibilidade pode explicar o debate tão agudo sobre o tema.

Mostra-se relevante o estudo das maneiras pelas quais se intenta conseguir coerência no âmbito do direito nacional, conferindo-se, pois, unidade e sistematicidade neste sentido. Destaca-se, por fim, a falta, no Brasil, de uma "teoria da coerência", a começar pelos critérios aqui apresentados, por exemplo. Afinal, contemporaneamente, a coerência é um assunto que perpassa todas as relações jurídicas. Da mesma forma, o assunto tem rendido intensas discussões jurídicas nas cortes de judiciárias. Basta visualizar os debates que se travam no limiar das relações de direito privado, quando invocada a cláusula da boa-fé objetiva, como um standard que intenta ser um "espaço" de convergência e de harmonia de pretensões contrapostas - só para tomar em conta um exemplo.

Para tanto, utilizar-se-á três perspectivas metodológicas, a perceber o objeto de estudo no plano analítico, no plano teleológico e no plano pragmático. Optou-se, neste caso, pela escolha do método fenomenológico, uma vez que ele não corresponde a um mero instrumento de descrição, ou seja, ao mesmo tempo em que permite a construção de uma revisão bibliográfica, também consiste em uma tarefa científica de interpretação crítica, a qual procura esclarecer principalmente os significados menos aparentes do tema pesquisado. A partir deste método, apresentamos cada um dos conteúdos, deixando evidente o "caminho científico" que toma por ponto de partida as bases teóricas de cada instituto, seguindo adiante com a exposição da sua operacionalidade no cotidiano das relações jurídicas. Essa avaliação destaca a configuração do conceito multidimensional do termo, porque o seu significado acaba por deter elementos dogmáticos diferentes para cada ramo da legislação que se ocupa da coerência. 
Revista Eletrônica de Direito Processual - REDP.

Rio de Janeiro. Ano 12. Volume 19. Número 2. Maio a Agosto de 2018

Periódico Quadrimestral da Pós-Graduação Stricto Sensu em Direito Processual da UERJ

Patrono: José Carlos Barbosa Moreira (in mem.). ISSN 1982-7636. pp. 149-172

www.redp.uerj.br

\section{Coerência jurídica}

A partir de tudo o que se disse até então, preliminarmente se pode afirmar que a consistência ${ }^{2}$ e a sistematicidade do direito pretendem evitar que existam contradições no limiar do ordenamento jurídico ${ }^{3}$. Atrelado a estes institutos, a coerência - a ser analisada nesta seção - também vem a qualificar o ordenamento jurídico, podendo ser considerada uma "exigência lógica" e "normativa" do direito ${ }^{4}$. Toda esta conjuntura possui ligação para com a noção de coerência, a exaltar sua importância prática, porque estamos, assim, diante de um problema posto pela realização do direito. A perspectiva dinâmica do sistema jurídico é que exalta a relevância do estudo da coerência, porque é neste momento que se percebe se o direito faz ou não sentido.

\section{Coerência no plano analítico}

\footnotetext{
2 Para a lógica, a consistência é a chave para o "princípio da não-contradição" (SAVIGNY, Friedrich Carl Von. Sistema del diritto romano attuale. Trad. Vittorio Scialoja. Torino: Utet (Unione Tipográfico-Editrice Torineze), v. 1, 1888, p. 267), uma vez que se a premissa "X" está concomitantemente evidenciada com sua negação “-X”, a lógica é inconsistente (GEACH, P. T. Razão e argumentação. Trad. Clarissa Vido, Gustavo Coelho, Luis Fellipe Garcia. Porto Alegre: Penso, 2013, p. 73-76). Em termos de ordenamento jurídico, existirá consistência dele quando não se perceberem antinomias, conflitos entre as disposições normativas ou incompatibilidades (GUASTINI, Riccardo. Interpretación, estado y constituición. Lima: Ara, 2010, p. 76). Em termos interpretativos, a profusão de argumentos deve ser vertida de modo racional e convincente.

3 O termo "ordenamento jurídico" pode ser considerado um sistema de atos normativos que disciplinam e determinam vinculativamente a sociedade ou parcela dela, tutelando aspectos da vida dos indivíduos. Em síntese, consubstancia-se como um conjunto de normas jurídicas. Contudo, este ordenamento não se resume a um manancial de regras somadas, mas sim, tal conjunto merece ser percebido em uma certa "unidade". Se o manancial de dispositivos estiver desarticulado, é certo que ele padeceria de toda sorte de contradições, o que minimizaria sensivelmente sua eficácia. Logo, o ordenamento jurídico não pode ser entendido como um simples somatório de normas. Necessita que o conjunto de disposições jurídicas esteja disposta em determinado sentido e para certo fim. Tércio Sampaio Ferraz Júnior (Introdução ao estudo do direito. Técnica, decisão, dominação. São Paulo: Atlas, 1994, p. 175) traz um exemplo elucidativo: um quadro, um giz, uma série de cadeiras e mesas não necessariamente formam uma sala de aula. Estes objetos podem estar dispostos em um depósito. A sala de aula é assim constituída - e a compreendemos como tal - quando há uma determinada disposição destes objetos, formando um todo que faz sentido.

${ }^{4}$ NEVES, Antônio Castanheira. Castanheira Neves. A unidade do sistema jurídico: o seu problema e o seu sentido. Boletim da Faculdade de Direito. Estudos em homenagem ao Prof. Doutora J. J. Teixeira Ribeiro. Coimbra: Universidade de Coimbra, número especial, 1979. p. 104-105. Norberto Bobbio entende que a coerência é uma exigência do ordenamento jurídico, mas não uma necessidade, "[...] no sentido de que a exclusão total de antinomias não é uma condição necessária para a existência de um ordenamento jurídico: um ordenamento jurídico pode tolerar normas incompatíveis no seu interior, sem se extinguir." (BOBBIO, Norberto. Teoria do ordenamento jurídico. Trad. Ari Marcelo Solon. São Paulo: EDIPRO, 2014, p. 115). Esta perspectiva pode ser aceita desde que tomemos como verdadeiras algumas premissas. Por exemplo: realmente, a coerência não é elemento do ordenamento. Como explicamos, é considerada um atributo dele. E tal ordenamento jurídico, caso incoerente, será acometido de um grave déficit de efetividade.
} 
Revista Eletrônica de Direito Processual - REDP.

Rio de Janeiro. Ano 12. Volume 19. Número 2. Maio a Agosto de 2018

Periódico Quadrimestral da Pós-Graduação Stricto Sensu em Direito Processual da UERJ

Patrono: José Carlos Barbosa Moreira (in mem.). ISSN 1982-7636. pp. 149-172

www.redp.uerj.br

Este é o típico instituto que tem significado e relevância para fora dos limites da ciência jurídica ${ }^{5}$. Aliás, é tão caro que a própria filosofia (inclusive do direito) tem total apreço pelo tema ${ }^{6}$. Bem por isto que tomaremos o cuidado de estruturar nossa perspectiva a partir de uma análise do fenômeno jurídico em relação ao tema.

Sob o aspecto etimológico, "coerência"7 é uma palavra que se associa a um substantivo para qualificá-lo ou subclassificá-lo. Logo, quando se diz que um ordenamento, um sistema jurídico, uma decisão é "coerente", estamos a atribuir uma propriedade a estes institutos ${ }^{8}$. Ao mesmo tempo, é importante notar que o termo impõe algo que deve ser ou que foi, ou seja, um estado de coisas a ser alcançado ou que foi alcançado. Enfim, algo coerente é algo que deve ser ou que assim o foi. E, se assim o é, a coerência impõe também limites, porque expõe aquilo que não deve ser, ou seja, algo que não é coerente.

Neste ponto, concordamos com Luhmann ${ }^{9}$, ao perceber que o direito como uma estrutura de generalização congruente, procurando firmar uma coerência na sua estrutura e na sua aplicação. Até porque não faria sentido o direito buscar ordenar as coisas - colocar as coisas em ordem - de modo incongruente ${ }^{10}$. Aliás, o sistema jurídico precisa fazer sentido para aquilo que se propõe, sob pena de deixar de ser efetivo. A desordem não é

\footnotetext{
${ }^{5}$ SKINNER, Quentin. Significado y compreensóin em la história de las ideias. Prismas: Revista de História Intelectual, n. 4, 2000, p. 159-165. O autor aborda o "mito da coerência" no que tange à metodologia histórica.

${ }^{6}$ Vários autores, cada qual da sua maneira e a partir de uma metodologia tão própria, enfrentaram o tema da coerência ou se utilizaram de termos com significação muito próxima ("vizinha"). Exemplo: Niklas Luhmann (El derecho de la sociedad. Trad. Javier Torres Nafarrate. México: Universidade Iberoamericana/Colección Teoria Social, 2005, p. 121).

7 Outros autores fazem uso do termo "congruência" no mesmo sentido que atribuímos, aqui, à palavra “coerência”. É o caso de Paolo Comanduci e Ricardo Guastini (Op. Cit., p. 243 e ss.), ao traduzirem, em sua obra, o termo da língua inglesa "coherence" para a palavra italiana "congruenza".

${ }^{8}$ ARMINJON, Pierre; NOL'DE, Boris Ėmmanuilovich (baron); WOLFF, Martin. Traité de droit compare. Paris: Librairie Générale de Droit et de Jurisprudence, t. 1, 1950, p. 10.

${ }^{9}$ LUHMANN, Niklas. Op. Cit., p. 121. Para o autor, o direito seria visto como uma "estrutura". E isto não retira dele seu caráter dinâmico, devido à permanente evolução provocada pela sua necessidade de constantemente atuar como uma das estruturas sociais que venham a minimizar a complexidade das possibilidades de ser no mundo.

${ }^{10}$ Nas palavras de Jorge Miranda: "O Direito não é mero somatório de regras avulsas, produto de atos de vontade, ou mera concatenação de fórmulas verbais articuladas entre si, o Direito é ordenamento ou conjunto significativo e não conjunção resultada de vigência simultânea; é coerência ou, talvez mais rigorosamente, consistência; é unidade de sentido, é valor incorporado em regra." (MIRANDA, Jorge. Manual de direito constitucional. Coimbra: Coimbra Editora, t. IV, 2000, p. 199)
} 
Revista Eletrônica de Direito Processual - REDP.

Rio de Janeiro. Ano 12. Volume 19. Número 2. Maio a Agosto de 2018

Periódico Quadrimestral da Pós-Graduação Stricto Sensu em Direito Processual da UERJ

Patrono: José Carlos Barbosa Moreira (in mem.). ISSN 1982-7636. pp. 149-172

www.redp.uerj.br

normal ao direito, nem à maioria das outras ciências - para não dizer a todas. Assim, o "remédio ao caos" seria a coerência ${ }^{11}$.

A noção de coerência sempre foi bastante relevante para Ronald Dworkin, especialmente quando trata do instituto da integridade ${ }^{12}$. Para o autor o sistema jurídico deve ser constituído, na medida do possível, de modo a expressar um sistema único e coerente de justiça e equidade na correta proporção ${ }^{13}$. De outro lado, os magistrados, para manter a integridade do direito, devem julgar os "casos difíceis" intentando manter um "[...] conjunto coerente de princípios sobre os direitos e deveres das pessoas, a melhor interpretação da estrutura política e da doutrina jurídica de sua comunidade."14. Neste último ponto, o magistrado seria um "co-autor de uma peça literária" que com os demais "escritores" escreveria uma "obra sem fim"15. O autor quer dizer que o magistrado não poderia se comportar como um "autor individual", desconsiderando a contribuição dos demais juristas. Além disso, quando decide, deve considerar o trabalho desenvolvido até então ${ }^{16}$.

Há uma peculiaridade na obra do autor: ele liga a coerência à moralidade. De modo que, tanto o legislador deveria constituir normas que fossem coerentes com moral da comunidade, assim como o magistrado deveria assim agir ao aplicar a lei. Logo, com base em uma "moralidade política" ", a decisão judicial deverá ser justificada com base em um conjunto de princípios que forneceriam uma explicação dita coerente. Sendo assim, as pessoas seriam julgadas, em cada caso, de acordo com este manancial de princípios, de modo justo e equitativo. Dito de outro modo, a coerência seria natural e indispensável em

\footnotetext{
${ }^{11}$ Parafraseando Henri Lefebvre (LEFEBVRE, Henri. $O$ direito à cidade. São Paulo: Centauro, 2001, p. 23). Um dos institutos que inspira o direito é dialética, a qual tem por base uma "diferença" de proposições entre dois interlocutores. O sistema jurídico nacional e de tantos outros países, estrutura espaços para que esta "dialética" possa ser vasada de modo minimamente ordenado, igualitário e equitativo, por exemplo. Daí a necessidade de se realçar a coerência como uma ferramenta e equalização das mencionadas "diferenças".

${ }^{12}$ DWORKIN, Ronald. Império do direito. Trad. Jefferson Luiz Camargo. São Paulo: Martins Fontes, 1999, p. 213.

${ }^{13}$ DWORKIN, Ronald. Op. Cit., p. 264.

${ }^{14}$ DWORKIN, Ronald. Op. Cit., p. 305.

${ }^{15}$ Por isso que a história assume papel importante nesse cenário.

${ }^{16}$ DWORKIN, Ronald. Uma questão de princípio. Trad. Luis Carlos Borges. São Paulo: Martins Fontes, 2000, p. 238 e ss. A adequação seria mecanismo de efetivação da coerência, advogando que o direito deve estar em conformidade com os princípios morais.

${ }^{17}$ A ideia de "moralidade política", para Dworkin, está ligada à igualdade. Baseia-se na compreensão de que as pessoas devem ser tratadas equitativamente. Assim, cada comunidade deve revelar os "seus preceitos morais, que serão essenciais à prática judicial (GUEST, Stephen. Ronald Dworkin, jurists: profiles in legal theory. Stanford University Press: Stanford, 1991, p. 33).
} 
Revista Eletrônica de Direito Processual - REDP.

Rio de Janeiro. Ano 12. Volume 19. Número 2. Maio a Agosto de 2018

Periódico Quadrimestral da Pós-Graduação Stricto Sensu em Direito Processual da UERJ

Patrono: José Carlos Barbosa Moreira (in mem.). ISSN 1982-7636. pp. 149-172

www.redp.uerj.br

cada decisão a ser produzida, sendo uma tarefa infinita ${ }^{18}$. Para o autor norte-americano, a

coerência reclamaria uma verdade, que se baseia em um conjunto de crenças.

A crítica que pode ser feita à teoria de Ronald Dworkin acerca da coerência consiste no fato de que o autor é por deveras otimista em relação à possibilidade de que um juiz consiga alcançar a tutela dos direitos por meio do reconhecimento de fundamentos axiológicos comuns. Isso pode ser considerado insustentável. Por outro lado, adotando a perspectiva do autor, tender-se-ia a se desconsiderar o pluralismo de ideias ou de valores ${ }^{19}$.

Neil MacCormick ${ }^{20}$ entende que o sistema jurídico, para ser coerente, deveria tomar em conta duas premissas: primeiro, é preciso que ele seja o mais detalhado possível, a fim de que possa dar conta de especificar os direitos da comunidade a ser tutelada. Ao mesmo tempo, princípios gerais dariam conta de estruturar este mesmo direito em premissas comuns. Isto tudo para que o mencionado sistema jurídico possa fazer sentido. Para tanto, o autor entende que a coerência reclama, na medida do possível, a ausência de contradições. E, de outro lado, a coerência deve estar de acordo com um "princípio geral" 21 .

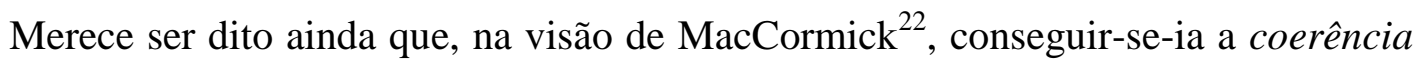
narrativa ao se revelar a verdade no sistema jurídico, o que se daria por meio da fundamentação. Defende que quem decide deve articular as proposições fáticas incidentes, a fim de perfazer um sentido. Assim como aquele que se propõe a expedir uma decisão deve deixar coerente uma narrativa que se trata de uma relação racional entre estas proposições, pressupondo que ocorreram no "tempo real". Enfim, este "tempo real" deve ser transportado ao "tempo da narração". Por isto que a verdade em MacCormick é uma "verdade por correlação", porque todas as proposições da narrativa devem estar coerentes com a totalidade delas e com os princípios gerais que estruturam o sistema normativo.

De qualquer sorte, para se analisar a coerência, devemos partir de um ponto. Significa dizer que tal noção, para ser minimamente definida, deverá, em termos metodológicos, perfazer uma série de comparações. Ora, para se dizer que algo coerente,

\footnotetext{
${ }^{18}$ VASCONSELLOS, Fernando Andreoni. Interpretação do direito tributário. Entre a coerência e a consistência. Curitiba: Juruá, 2014, p. 31.

${ }^{19}$ GUASTINI, Ricardo. Op. Cit., p. 76.

${ }^{20}$ MacCORMICK, Neil. Retórica e o Estado de Direito: Uma teoria da argumentação jurídica. Trad. Conrado Hübner Mendes e Marcos Paulo Veríssimo. Rio de Janeiro: Elsevier, Campus, 2008., p. $250-251$.

${ }^{21}$ MacCORMICK, Neil. Op. Cit., p. 250. Neste ponto o autor se aproxima de Ronald Dworkin na defesa de que princípios fornecem (ou tendem a fornecer) coerência às regras.

${ }^{22}$ MacCORMICK, Neil. Op. Cit., p. 250-251.
} 
Revista Eletrônica de Direito Processual - REDP.

Rio de Janeiro. Ano 12. Volume 19. Número 2. Maio a Agosto de 2018

Periódico Quadrimestral da Pós-Graduação Stricto Sensu em Direito Processual da UERJ

Patrono: José Carlos Barbosa Moreira (in mem.). ISSN 1982-7636. pp. 149-172

www.redp.uerj.br

devemos saber, ao menos amplamente, o que não é coerente. Por isto, os critérios que fornecem coerência ao sistema dirão que ele assim o é em determinado sentido, sendo que outro ordenamento será (ou poderá ser) coerente em outro sentido ${ }^{23}$.

E, ainda, merece ser feita outra advertência: os critérios de coerência não são condições de validade do sistema jurídico, mas sempre condição para a justiça do ordenamento. Veja a seguinte situação: certo magistrado está diante de duas normas contraditórias válidas, e passíveis de serem aplicadas, sendo que é indiferente à incidência de qualquer uma delas. Neste caso, o sistema apresenta uma violação à segurança jurídica e à igualdade, porque o cidadão não conseguiria prever, respectiva e minimamente, o resultado da decisão (judicial, administrativa etc.), nem se receberia o mesmo tratamento ${ }^{24}$.

O direito quer regular a vida em sociedade. Então, a ele é imanente a ideia de universalidade, ao se tentar racionalizar a vida prática, de modo que as normas não podem ser consideradas isoladamente, mas em conjuntos dotados de sentido. Um ordenamento contraditório guiará os sujeitos prejudicialmente ${ }^{25}$. Mas, para tanto, o "teste" de que algo é coerente deveria partir de certas premissas, comparações, deduções, ou vir a emprega-las, seja para com o ordenamento, seja para com os fatos que cercam as decisões (coerência narrativa).

O certo é que os critérios de coerência não têm a potencialidade de eliminar toda e qualquer contradição. De qualquer sorte, prestam-se a minimizá-las de modo substancial. E por isto é que tais critérios possuem um caráter muito mais formal do que substancial, porque não se preocupam imediatamente com o conteúdo do ordenamento jurídico. Por isto que a coerência não é uma questão de verdade, mas sim, uma questão de racionalidade ${ }^{26}$.

De outro lado, partindo das noções de "ordenamento jurídico" e de "sistema jurídico", devemos tratar do problema das lacunas do direito, que é sensível no tema da

\footnotetext{
${ }^{23}$ ALEXY, Robert. Constitucionalismo discursivo. Trad. Luís Afonso Heck. Porto Alegre: Livraria do Advogado, 2015, p. 129-130.

${ }^{24}$ BOBBIO, Norberto. Teoria do ordenamento jurídico. Trad. Ari Marcelo Solon. São Paulo: EDIPRO, 2014, p. 111

${ }^{25}$ Veja que o mundo fenomênico pode ser explicado de modo racional, a ser compreendido, na decisão, por meio de uma justificação também racional. É certo que toda "explicação" é simplesmente provisória, porque pode ser revisada. Isto somente não será mais possível, ao menos em termos de processo judicial, quando o direito coloca um limite formal, em nome da segurança jurídica: quando, por exemplo, há a formação da coisa julgada material.

${ }^{26}$ ATIENZA, Manuel. Las razones del derecho. Teorías de la argumentación jurídica. México: Universidade Autônoma de México, 2005, p 120.
} 
Revista Eletrônica de Direito Processual - REDP.

Rio de Janeiro. Ano 12. Volume 19. Número 2. Maio a Agosto de 2018

Periódico Quadrimestral da Pós-Graduação Stricto Sensu em Direito Processual da UERJ

Patrono: José Carlos Barbosa Moreira (in mem.). ISSN 1982-7636. pp. 149-172

www.redp.uerj.br

coerência. Como vimos, especialmente no Século $\mathrm{XIX}^{27}$, a estruturação do direito em um

sistema teve por meta, dentre outras, evitar que o ordenamento permanecesse incompleto.

Surge, assim, a figura da integração, ao lado da unidade, que serviria para purgar as contradições.

Primeiramente, vamos partir da premissa de que já foi mais do que provado que a completude será uma intenção, mas não algo que possa necessariamente ser alcançado. De modo que o intérprete, é claro, terá de conviver com a presença de lacunas, e que o juiz deva julgar todas as controvérsias a ele apresentadas para exame, ainda que se depare com estas lacunas ${ }^{28}$.

Por isso, devemos perguntar se a incompletude do ordenamento pode prejudicar a coerência. A priori, a resposta a esta pergunta é positiva, e, para tanto, caberia ao intérprete purgar eventual lacuna que eventualmente deixaria o ordenamento sem sentido - veja não estamos a falar em contradição. Vamos a um exemplo: o art. 23 da Lei no 8.429/92 (Lei de Improbidade Administrativa) prevê, no inciso II, prevê que os atos de improbidade praticados por detentores de cargo ou de emprego público prescrevem no mesmo prazo da prescrição da pena administrativa de demissão - prevista na lei que rege cada cargo ou emprego público. Contudo, se focarmos no empregado público, percebemos que os direitos e deveres dele estão previstos na Consolidação das Leis do Trabalho (CLT). E, diante deste panorama, veremos uma lacuna, porque não há prazo de prescrição da pena de demissão prevista na referida CLT, Logo, a remissão feita pela Lei de Improbidade Administrativa não possui sentido - v.g. é incoerente. Sendo assim, cabe ao intérprete solucionar a incoerência causada pela lacuna da $1 \mathrm{ei}^{29}$.

Enfim, queremos dizer com isto que a técnica da analogia, por exemplo, que tem por meta resolver o problema das lacunas, poderá também deixar o sistema coerente

\footnotetext{
${ }^{27}$ Por todos: SAVIGNY, Friedrich Carl Von (Op. Cit.). Muito embora este autor se opunha à ideia de codificação, entrando em conflito, à época, com as ideias de Anton Friedrich Justus Thibaut, o qual defendia abertamente a confecção de um Código Civil, por exemplo. De todo modo, mesmo a figura dos códigos sofreu o reflexo da mencionada "crise" do ordenamento produzido pelo "Estado legislativo", de acordo com o que anuncia Gustavo Zagrebelski (El derecho dúctil. Madrid: Trotta, 2003, p. 39)

${ }^{28}$ BOBBO, Norberto. Op. Cit., p. 119-123. Esta "revolta" ao fetichismo da lei e à ideia de que o direito deveria ser "completo" pode ser visto em várias obras, como a de Jean Cruet (A vida do direito e a inutilidade das leis. Leme: Edijur, 2003) e a de Karl Engish (Introdução ao Pensamento Jurídico. Lisboa: Fundação Calouste Gulbekian, 1977).

${ }^{29}$ No caso, visualizamos duas possibilidades: ou se aplica ao empregado público, por analogia, o disposto no inciso I do art. 23 da Lei de Improbidade Administrativa, valendo o prazo de prescrição de cinco anos do desligamento do referido agente público. Ou se aplicaria, também por analogia, o prazo prescricional da pena de demissão da lei geral que trata do estatuto dos cargos públicos de determinado ente, caso existente.
} 
Revista Eletrônica de Direito Processual - REDP.

Rio de Janeiro. Ano 12. Volume 19. Número 2. Maio a Agosto de 2018

Periódico Quadrimestral da Pós-Graduação Stricto Sensu em Direito Processual da UERJ

Patrono: José Carlos Barbosa Moreira (in mem.). ISSN 1982-7636. pp. 149-172

www.redp.uerj.br

quando justamente estiver evidenciada este tipo de omissão. Em outros termos, completude

e coerência possuem conteúdos diversos, mas não necessariamente se opõem. Sabemos bem que as técnicas para resolução dos dois problemas serão diversas. Contudo, queremos provar duas coisas: que a incoerência do sistema jurídico pode ser causada pela lacuna. E, claro, que as técnicas de solução deste problema podem servir para dar sentido ao ordenamento.

\section{Coerência no plano horizontal}

Um sistema jurídico será coerente quando, no plano horizontal, ou seja, quando estivermos diante de dispositivos de mesmo nível, não se evidenciarem contradições ${ }^{30}$ consistência, bem como fazem sentido com o todo (coerência). Neste caso, a solução ou interpretação aos problemas jurídicos não necessita procurar as fontes de validade de uma regra, mas sim, critérios de "revogação", como ocorrem com os parâmetros hermenêuticos cronológico e da especialidade. Aqui, o ordenamento jurídico deve ser visualizado como um todo, em completude, buscando-se uma consonância para com as regras e também para com os princípios.

Além disso, as normas devem "fazer sentido" entre si, tendo em vista que devem estar racionalmente relacionadas entre si, ou para com um conjunto harmônico de "normas superiores". Tais dispositivos de hierarquia maior possuem como vocação à realização de alguns valores comuns. Sendo assim, a coerência, neste plano, acaba por ser concebida como uma "coerência de justificação", a fim de que duas normas de mesma hierarquia, apesar de diferentes, possam fazer sentido ${ }^{31}$. Vamos a um exemplo: seria incoerente pensar que um Tribunal considerasse o serviço de acesso à rede mundial de computadores, como "serviço público" para fins tributários, e não estabelecesse o mesmo entendimento em termos de direito administrativo. Em outros termos, não faria sentido, neste caso específico, que as empresas provedoras do acesso à internet fossem consideradas imunes

\footnotetext{
${ }^{30}$ VASCONSELLOS, Fernando Andreoni. Op. Cit., p. 23.

${ }^{31}$ MacCORMICK, Neil. Legal reasoning and legal theory. Oxford: Oxford University Press, 1978, p. 52; MITIDIERO, Daniel. Cortes Superiores e Cortes Supremas: do controle à interpretação, da jurisprudência ao precedente. São Paulo: Revista dos Tribunais, 2014, p. 86.
} 
Revista Eletrônica de Direito Processual - REDP.

Rio de Janeiro. Ano 12. Volume 19. Número 2. Maio a Agosto de 2018

Periódico Quadrimestral da Pós-Graduação Stricto Sensu em Direito Processual da UERJ

Patrono: José Carlos Barbosa Moreira (in mem.). ISSN 1982-7636. pp. 149-172

www.redp.uerj.br

de tributação quanto a esta atividade, e ela, da mesma forma, não fosse considerada "serviço público"32.

\section{Coerência no plano vertical}

O sistema jurídico pode ser estruturado de modo assimétrico, ou seja, há proposições alocadas em níveis hierárquicos, sendo que o estamento superior daria validade ao inferior - como é o sistema nacional. Assim, no plano vertical, um sistema será considerado coerente se o sistema de inferências não revelar distinções anormais em situações iguais.

Aqui, a coerência será buscada na medida em que não há contradição entre uma ou algumas proposições jurídicas que dão apoio a estamentos legais de hierarquia diversa. De qualquer sorte, é evidente que a estrutura vertical do ordenamento trabalha mais com a questão de validade, do que com o tema da coerência.

\section{Coerência do ordenamento jurídico - perspectiva negativa}

Efetivamente, a coerência pode deter duas perspectivas. Primeiro, o ordenamento, ex ante, deve sustentar uma unidade que não contemple contradições internas. De outro lado, ainda que não as detenha, quando o intérprete, porventura, valer-se do mencionado manancial de normas a ele dispostas, deverá evitar que surjam incoerências não visualizadas - sendo esta a dita perspectiva positiva sobre o tema ${ }^{33}$.

Dito de modo objetivo, a perspectiva negativa pretende que o ordenamento jurídico detenha coerência quando determina que nele não se evidenciem antinomias. Sendo assim, normalmente esta perspectiva se dirige ao legislador, que é aquele que, por excelência, produz e amplia o manancial de dispositivos que compõe o ordenamento jurídico ${ }^{34}$. É como se existisse uma "sobreregra" (acima das demais) que dissesse ao legislador: "não cries normas que sejam incompatíveis com as demais".

\footnotetext{
${ }^{32}$ Lembrando que o Superior Tribunal de Justiça considerou que as empresas provedoras de acesso à rede mundial de computadores não prestavam "serviço público" e, portanto, não poderiam gozar de imunidade tributária. Conferir: STF, Informativo no 246.

${ }^{33}$ Quando Ronald Dworkin (Op. Cit., p. 213) está a explicitar sua noção de integridade do sistema jurídico, aponta, na mesma medida, que ela se aplica tanto no processo legislativo, como às decisões judiciais.

${ }^{34}$ BOBBIO, Norberto. Op. Cit., p. 109.
} 
Revista Eletrônica de Direito Processual - REDP.

Rio de Janeiro. Ano 12. Volume 19. Número 2. Maio a Agosto de 2018

Periódico Quadrimestral da Pós-Graduação Stricto Sensu em Direito Processual da UERJ

Patrono: José Carlos Barbosa Moreira (in mem.). ISSN 1982-7636. pp. 149-172 www.redp.uerj.br

Assim, aqui, os critérios que eliminam as antinomias ganham relevância. Vamos a um exemplo: o administrador público que se propõe a regular uma regra superior ( $v . g$. uma lei ordinária) não poderá atuar contra legem. Assim, a autorregulação - subproduto da autolimitação administrativa - deve, no mínimo e por primeiro, obedecer à hierarquia. Na hipótese de se estar diante de normas de mesmo nível, os critérios da especialidade e da cronologia darão cabo de solucionar a questão (v.g. norma especial prevalece sobre a geral; norma posterior prevalece em relação à anterior $)^{35}$.

A objetividade do ordenamento é outro fator de extrema importância em termos de intensificação da coerência. O direito ganhará a confiança da sociedade quanto maior for a objetividade do ordenamento e da sua interpretação. Tal objetividade será alcançada se vários intérpretes, obrigados a aplicar certo ordenamento, independentemente dos seus vieses ideológicos, sentirem-se obrigados a chegar a mesmo resultado ${ }^{36}$.

\section{Coerência da interpretação do ordenamento jurídico - perspectiva positiva}

A concretização do direito não ocorre sem disputas e sem oposições ${ }^{37}$. E isto se percebe claramente nas decisões judiciais, quando o juiz deve debater os "novos problemas" que são postos perante si. E deve resolver estas questões de modo coerente. Vamos a um exemplo: a incidência de um inciso contido em um parágrafo de um artigo na lógica da subsunção - não permite concluir, necessariamente, que se está a aplicar todo o artigo ou todo um código. Mas esta incidência, aplicada sob o domínio da interpretação do texto, deve ser coerente com o restante do sistema jurídico.

Vale dizer, portanto, que a coerência é uma condição fundamental da racionalidade do decidir $^{38}$. Tal racionalidade será evidentemente demonstrada pela

\footnotetext{
35 Conferir, para tanto, a exposição detalhada feita por Norberto Bobbio (Op. Cit., p. 93-98). Aliás, o problema das "antinomias" - e, por conseguinte, a necessidade de se estabelecer uma metodologia de superação - não é nova. Por exemplo, já em Savigny percebemos um esforço grande em estabelecer mecanismos e procedimentos para a eliminação ou correção destes vícios no ordenamento. As contradições ou antinomias eram compreendidas, pelo autor, como uma "falta de unidade negativa" do ordenamento jurídico. Já as lacunas eram reputadas como sendo uma "falta de unidade positiva". A cada um destes problemas, o autor oferece um método de solução (CHIASSONI, Pierluiggi. L'indirizzo analítico nella filosofia del diritto. I. Da Benthan a Kelsen. Torino: Giappichelli Editore, 2009, p. 284-285).

${ }^{36}$ Aqui, existirá, é certo, uma atuação impessoal (ARRUDA, Thais Nunes de. Juízes e casos difíceis. O pragmatismo de Richard Posner e a crítica de Ronald Dworkin. Curitiba: Juruá, 2014, p. 107).

${ }^{37}$ COING, Helmut. Elementos fundamentais da filosofia do direito. Porto Alegre: Sérgio Fabris, 2002, p. 202.

${ }^{38}$ A frase, em outros termos, é de Robert Alexy (Op. Cit., p. 117).
} 
Revista Eletrônica de Direito Processual - REDP.

Rio de Janeiro. Ano 12. Volume 19. Número 2. Maio a Agosto de 2018

Periódico Quadrimestral da Pós-Graduação Stricto Sensu em Direito Processual da UERJ

Patrono: José Carlos Barbosa Moreira (in mem.). ISSN 1982-7636. pp. 149-172

www.redp.uerj.br

fundamentação ${ }^{39}$. Em assim sendo, podemos perceber que a clareza, a congruência e a

veracidade dos fundamentos, enfim, toda sistematicidade e lógica da decisão trará maior possibilidade de se conferir a sua coerência. Assim, a qualidade da estrutura da fundamentação será proporcional a se conseguir uma maior coerência da aplicação do ordenamento jurídico. Por isto que a perspectiva dita "positiva" se dirige ao intérprete, porque a coerência pressupõe uma prévia e adequada formação de entendimentos ${ }^{40}$.

Logo, certos cânones podem indicar um maior ou um menor grau de coerência nas decisões. Por exemplo: uma decisão é fundamentada por outras declarações deste sistema jurídico; há um enlace entre as diversas decisões; as premissas das quais partem as decisões são comuns; etc. Devemos perceber, ainda, que há certas premissas que enaltecem primazias entre princípios frente a situações comuns. Aliás, postulados gerais tendem a aumentar a coerência do sistema, porque organizam premissas objetivas no que se refere à interpretação do ordenamento jurídico.

O reconhecimento do argumento será fundamental para saber se há coerência na aplicação do ordenamento jurídico. Por exemplo: o "teste de razoabilidade"41 seria uma ferramenta importante a se reconhecer falácias e para estabelecer padrões de validade. As afirmações são justificáveis por argumentos e, em assim sendo, a lógica dará ferramentas a,

\footnotetext{
${ }^{39}$ Não é à toa que Aleksander Peczenik (On law and reason. Lexington: Springer, 2009, p. 131) afirme que uma condição mínima a se ter coerência consiste na existência de precedentes bem fundamentados. No Brasil, incide à espécie o disposto, por exemplo, no art. 489, § $1^{\circ}$ e no art. $927, \S 1^{\circ}$, ambos do CPC.

${ }^{40}$ A coerência (e a própria consistência, de acordo com a diferenciação por nós feita nos itens precedentes) é encontrada no enfrentamento dos argumentos suscitados para a formação da decisão jurídica. O detalhamento da fundamentação tende a gerar decisões mais consistentes e coerentes (PECZENIK, Aleksander. Op. Cit., p. 133).

${ }^{41}$ No caso Lawton v. Steele (1894), o Justice Brown conferiu as linhas mestras do "teste de razoabilidade", utilizado até hoje em todo o mundo: (a) o interesse no caso deve ser geral; a Suprema Corte carece de interferência quando a intervenção é meramente particular; (b) verificação da necessidade da constrição do direito para o alcance do fim pretendido. A suprema corte estadunidense definiu como seria feito o teste de razoabilidade, ou seja, como se processaria a trajetória para se aplicar o instituto. Para a aplicação da razoabilidade, certos questionamentos devem ser respondidos, o que seriam seus elementos centrais. $\mathrm{O}$ esquema apresentado a seguir influenciou o mundo inteiro, sendo de extrema valia hermenêutica a qualquer jurista ou legislador: (a) Avaliação do valor alegado como constrito: (a1) o bem ou a liberdade são tutelados pelo due process of law? (a2) esta restrição provém de um agente estatal? (a3) qual o grau de restrição? (b) Avaliação do fim escolhido que o Estado quer promover: (b1) o fim é constitucionalmente aceito ou possível? (b2) o fim corresponde aos reais motivos da restrição? (c) Avaliação dos pesos dos valores postos em jogo: (c1) há nexo de causa entre o meio escolhido e o fim pretendido? (c2) não existe meio menos intrusivo? (c3) o fim tem um peso suficiente para justificar a restrição? A razoabilidade, assim, ficou claramente definida no limiar do comon law. A perspectiva aqui apresentada foi retirada da obra de Letícia de Campos Velho Martel (Devido processo legal substantivo - razão absoluta, função e características de aplicabilidade. A linha decisória da Suprema Corte estadunidense. Rio de Janeiro: Lumen Juris, 2005, p. 370371).
} 
Revista Eletrônica de Direito Processual - REDP.

Rio de Janeiro. Ano 12. Volume 19. Número 2. Maio a Agosto de 2018

Periódico Quadrimestral da Pós-Graduação Stricto Sensu em Direito Processual da UERJ

Patrono: José Carlos Barbosa Moreira (in mem.). ISSN 1982-7636. pp. 149-172

www.redp.uerj.br

inclusive, verificar estes argumentos. Assim, pode-se perceber que algo é coerente quando está de ou em acordo com uma coisa ${ }^{42}$.

Neste sentido, "argumento"43 não necessariamente é apenas refutação, mas também, uma forma de estabelecer uma coerência interpretativa do sistema, enfim, uma conclusão comum, a se chegar em uma posição consensual ${ }^{44}$. Em algum momento, pode ser que o argumento não seja uma série de colocações para contradizer alguém.

Uma linha argumentativa coerente, de alguma maneira, teria de conter uma série conectada entre conclusões e premissas, ou seja, que permitem dar razões à conclusão. As premissas dever fornecer razões para dar lastro às conclusões ${ }^{45}$. Assim, para se ter coerência de um discurso, não basta uma "explicação", porque se reclama "justificação", na medida em que o primeiro instituto não é suficiente, não dá conta de persuadir. Em outros termos, a justificação é mais completa. Ambos os institutos são ordens lógicas diferentes, até porque explicação diz menos do que a justificação. E esta última categoria pode existir sem deter uma explicação. É quando não se sabe o porquê de uma ação.

A organização lógica do pensamento pode se dar por meio de "condicionais", lastreados em antecedentes e em consequentes. Usa-se as palavras "se", "caso", "desde que” etc. A avaliação de um argumento deverá partir destes condicionantes. Assim, a coerência da interpretação do ordenamento - perspectiva positiva - consiste em um conjunto de proposições organizadas que podem ser inferidas a partir de premissas, sendo este conjunto estruturado em um diálogo coerente.

\footnotetext{
${ }^{42}$ Exemplo: quando se cita inúmeros julgados, está-se tomando por base um argumento de autoridade. Só que isto pode ser uma falácia. Tenta-se, com isto, conseguir evidências que, muitas vezes, não tem base qualquer na lógica consistente - lembrando a diferença da consistência, para com a coerência.

43 "Argumento" é uma sequência de proposições que pretende produzir, alterar ou extinguir crenças ou comportamentos. A produção, alteração ou extinção de crenças deveriam partir de argumentos, enfim, ser conclusões. Contudo, as conclusões podem bem vir a ser argumentos. E, para tanto, determinados argumentos possuem mais ou menos potência, mais ou menos força. Por exemplo: por vezes dados são mais fortes do que súplicas. Por isto que, em certas situações, há argumentos de autoridade fixados consensualmente, e que subordinam as pessoas. Imagine que um guarda de trânsito tenha de fundamentar, a todo momento que o sinal verde significa "dar início à marcha dos veículos". Por isso é significativo que a linha argumentativa deva ser questionada em qualquer momento, seja nas premissas, seja nas proposições.

${ }^{44}$ Em outros termos, a perspectiva positiva da coerência estabelecerá uma mediação racional-discursiva entre o plano abstrato do ordenamento e a ordem jurídica concreta.

${ }^{45}$ Vamos fazer um exercício simples para provar e para explicar nossa linha de raciocínio. Em alguns textos, há palavras que "demarcam" as premissas e que determinam conclusões. Funcionam como marcadores de premissas os termos: "como", "suponhamos que", "no entanto", "visto que", "na hipótese de que" etc. Funcionam como marcadores de conclusões as palavras: "portanto", "logo", "então", "assim sendo", "posto isso", "de acordo com isto", "em função de" etc.
} 
Revista Eletrônica de Direito Processual - REDP.

Rio de Janeiro. Ano 12. Volume 19. Número 2. Maio a Agosto de 2018

Periódico Quadrimestral da Pós-Graduação Stricto Sensu em Direito Processual da UERJ

Patrono: José Carlos Barbosa Moreira (in mem.). ISSN 1982-7636. pp. 149-172 www.redp.uerj.br

Então, o problema da conservação ou da criação do direito consiste em estabelecer os limites ou premissas à atuação do intérprete que produzirá uma decisão, a fim de se obter toda sorte de coerência, enfim, que o direito faça sentido. E isto, é claro, não elimina a possibilidade de uma modificação no entendimento até então vigente, desde que, como dito, isto ainda faça sentido. Assim, devemos discutir o papel político da jurisdição, e como o sistema jurídico organiza o conjunto de demais decisões e fontes do direito.

Neste cenário, a coerência poderia ser mantida ainda que diante de uma interpretação conservativa ou criativa do direito. A primeira narra o direito atual, ao passo que a noção criativa pretende legitimar o direito existente, fazendo com que a decisão, apesar de não necessariamente ser estabelecida em continuidade, ainda tem sentido.

Podemos perceber insucessos em uma série de metodologias para se aplicar o direito ao caso concreto, enfim, quando se está a decidir. Vamos a alguns exemplos ${ }^{46}$ :

- Mesmo a interpretação conservativa semântica, que forneceria um sentido literal do texto, partindo, portanto, de uma determinação linguística, corre o perigo de ignorar os fins do direito.

- Ou a interpretação original ou histórica poderia, quiçá, ignorar o próprio aspecto semântico ou a realidade que se apresenta, e que pode ter se modificado no tempo. Sem contar que se deixa de lado o aspecto sistêmico do direito, porque esta última categoria é um conjunto de autoridades, e não focado só no legislador. É uma prática autorefutável.

- A interpretação sistemática pode criar direito ou conservá-lo. Mas o objetivo do direito, entre outros, é conseguir uma convergência, o que revela a noção de segurança jurídica.

Toda a exposição feita neste tópico reforça a ideia de que a coerência precisa ser alcançada também na aplicação do direito, o que se dá por variadas maneiras. E, neste aspecto, mostra-se relevante o estudo das técnicas de argumentação jurídica.

\section{Coerência na dimensão externa}

\footnotetext{
${ }^{46}$ Antonin Scalia (A matter of interpretation. Federal courts and the law. New Jersey: Princenton University Press, 1997, p. 16-18) percebe os problemas sérios da interpretação, mesmo quando fala sob as bases do comon law. Reflete a dificuldade, por exemplo, de revelarmos "intenção da legislação" ("the intent of legislature"), agregada a vários fatores, como aqueles ligados a questões pessoais do julgador, a problemas históricos, à indeterminação do texto etc.
} 
Revista Eletrônica de Direito Processual - REDP.

Rio de Janeiro. Ano 12. Volume 19. Número 2. Maio a Agosto de 2018

Periódico Quadrimestral da Pós-Graduação Stricto Sensu em Direito Processual da UERJ

Patrono: José Carlos Barbosa Moreira (in mem.). ISSN 1982-7636. pp. 149-172 www.redp.uerj.br

A perspectiva externa da coerência visualiza as decisões judiciais comparando-as com o todo, ou seja, mais especificamente, com as decisões já produzidas, a dialogar com a linha jurisprudencial já produzida. Ressalvada as hipóteses de superação, os tribunais não poderiam contrariar sua própria linha de entendimento, a se comportar, no caso, contraditoriamente.

Mesmo os casos em que se pratica um overruling $^{47}$, há de se ter coerência, enfim, a decisão que destoa da linha histórica já praticada deverá ser condizente com a realidade e com o sistema jurídico como um todo ${ }^{48}$. Por exemplo: seria incoerente fazer distinção entre a Lei de Improbidade (Lei $\mathrm{n}^{\circ}$ 8.429/92) e a Lei Anticorrupção (Lei $\mathrm{n}^{\mathrm{o}}$ 12.846/13) em termos de competência para legislar. Na mesma linha, violaria o instituto ora tratado a distinção (distinguishing ${ }^{49}$ ) entre núcleos de prática jurídica de instituições federais de ensino e núcleos de prática jurídica de instituições particulares de ensino, reconhecendo apenas aos primeiros o benefício da dobra dos prazos processuais, ainda sob a égide do CPC de $1973^{50}$.

A dimensão externa, como podemos ver, releva o caráter histórico do direito, especialmente quando se percebe como as decisões judiciais sucessivas podem construir o direito - e isto não pode ser ignorado. Tomando por base novamente a figura do precedente, veja que o magistrado poderá desconsiderá-lo, superá-lo, mas nunca o ignorar. Há um dever de dialogar com ele ${ }^{51}$.

Aqui, pode ser retomada a ideia de Dworkin ${ }^{52}$, antes mencionada, no sentido de que as decisões judiciais seriam parte de uma "grande obra literária", sendo ela um "capítulo" de um "trabalho infinito". Esta percepção de todo, a se perfazer uma autorreferência, é medida imposta pela dimensão externa da coerência.

\footnotetext{
${ }^{47}$ Overrruling, em apertada síntese, é prática processual que desconsidera a linha de precedentes já formada, e passa a adotar outra "razão de decidir" (ratio decidendi).

48 "“.... Nessa perspectiva, a superação total de precedente da Suprema Corte depende de demonstração de circunstâncias (fáticas e jurídicas) que indiquem que a continuidade de sua aplicação implicam ou implicarão inconstitucionalidade. 8. A inocorrência desses fatores conduz, inexoravelmente, à manutenção do precedente já firmado.” (STF, RE nº 655.265, Rel. Min. Luiz Fux, Rel. para Acórdão Min. Edson Fachin, Pleno, j. 13/04/2016).

${ }^{49} \mathrm{O}$ distinguishing ocorre quando não se aplica o precedente ao caso concreto, porque este último não é albergado pela eficácia do primeiro. Não se trata de uma mudança nos precedentes (overruling).

${ }^{50}$ Existe decisão judicial que não extende o benefício processual ao núcleo de prática jurídica de entidade privada (STJ, AgRg no AgRg no AgRg na MC nº 5.149/MG, Rel. Min. Carlos Alberto Menezes Direito, $3^{\mathrm{a}}$ Turma, j. 15/10/2002).

${ }^{51}$ BARBOZA, Estefânia Maria de Queiroz. Precedentes judiciais e segurança jurídica - fundamentos e possibilidades para a jurisdição constitucional brasileira. São Paulo: Saraiva, 2014, p. 235

${ }^{52}$ DWORKIN, Ronald. Op. Cit., p. 238 e ss.
} 
Revista Eletrônica de Direito Processual - REDP.

Rio de Janeiro. Ano 12. Volume 19. Número 2. Maio a Agosto de 2018

Periódico Quadrimestral da Pós-Graduação Stricto Sensu em Direito Processual da UERJ

Patrono: José Carlos Barbosa Moreira (in mem.). ISSN 1982-7636. pp. 149-172

www.redp.uerj.br

\section{Coerência na dimensão interna}

Já a dimensão interna da coerência foca na fundamentação de cada decisão, ou seja, na articulação dos $\operatorname{argumentos}^{53}$. Esta lógica impõe, então, que a motivação seja exposta a partir de três critérios, ou seja, deve se basear em três parâmetros: necessita ser explícita, clara e congruente. Se pudéssemos reunir estas três características em uma só, poderíamos dizer que a motivação deve ser coerente.

O destinatário do ato que se vê diante de uma fundamentação imprecisa, no mais das vezes, acaba por estar na mesma situação daqueles que estão frente a uma decisão imotivada. Ora, a impossibilidade de compreensão da fundamentação acaba por trazer, em certa medida, os mesmos efeitos de uma decisão que não possui qualquer exposição de motivos. Compreender mal é não compreender.

Tal dimensão preocupa-se em fornecer um verdadeiro direito de compreender a decisão. A clareza na exposição de motivos torna-se, a partir da dicção desta "regra", um verdadeiro "direito subjetivo". Não se admite uma motivação implícita ou secreta, o que, no caso, seria típica incoerência ${ }^{54}$. Assim, deve ser exposta de maneira objetiva e clara, a se ter fácil condição de compreender o julgamento ${ }^{55}$.

Por exemplo: a motivação não se pode se limitar a invocar a cláusulas vagas como razão de decidir, como quando o dispositivo é fundamentado apenas na "cláusula do interesse público", ou quando se utilizam de afirmações vagas etc. ${ }^{56}$. O que não se pode admitir é a exposição de motivos de modo obscuro, ininteligível ou contraditório. No caso, atentar-se-ia contra a segurança jurídica, porque se estaria diante de uma motivação incerta.

Em melhores termos, a motivação deverá ser congruente, pertinente e suficiente. Por exemplo, a motivação deve possuir nexo para com as provas e as pretensões constantes no processo em que é exarada - eis a coerência interna exigida. Assim, a exposição de

\footnotetext{
${ }^{53}$ PECZENIK, Aleksander. Op. Cit., p. 131.

${ }^{54}$ Salvo os casos expressamente admitidos pelo ordenamento jurídico, como é o caso das decisões proferidas pelo plenário do tribunal do júri (art. $5^{\circ}$, inciso XXXVIII, alínea $b$, da CF/88).

${ }^{55}$ A percepção de que a motivação deve ser clara e precisa, expressada, portanto, em uma fórmula exata, já era, há muito, defendida por Gaston Jèze (Principios generales del derecho administrativo. Buenos Aires: Depalma, v. 3,1982, p. 235).

${ }^{56}$ STJ, MS no 9.944-DF, Rel. Min. Teori Albino Zavascki, $1^{\text {a }}$ Seção, j. 25/05/2005.
} 
Revista Eletrônica de Direito Processual - REDP.

Rio de Janeiro. Ano 12. Volume 19. Número 2. Maio a Agosto de 2018

Periódico Quadrimestral da Pós-Graduação Stricto Sensu em Direito Processual da UERJ

Patrono: José Carlos Barbosa Moreira (in mem.). ISSN 1982-7636. pp. 149-172

www.redp.uerj.br

motivos deve ser dispensada de maneira harmônica e lógica, estando razoavelmente

disposta de acordo com os fatos provados no limiar do procedimento.

\section{Coerência no plano teleológico}

Cada grupo humano precisa se organizar de acordo com uma determinada ordem, de modo a evitar disputas que prejudiquem a própria sobrevivência do mencionado grupo. E o direito tem uma missão bastante essencial: dar direção a esta coletividade. Portanto, é inerente ao direito a ausência contradições internas, sendo algo natural ao seu fim. Explico: não se teria como conseguir a "paz social" ou a "harmonia da coletividade" em meio a contradições jurídicas ou à ausência de sentido. Pensamos que justamente as incoerências gerariam mais e mais disputas. Basta tomar em conta que uma lei dúbia ou contraditória possui grande possibilidade de gerar um número considerável de demandas judiciais.

Além disso, um dos fins do direito é a busca pela segurança ${ }^{57}$. E ele garante isto com base em sua inviolabilidade, até porque, aquilo que é determinado pela legalidade, é excluído da arbitrariedade, uma vez que ninguém deveria violá-10 ${ }^{58}$. Para tanto, devem ser constituídas instituições para se esclarecer e para manter o direito coerente ${ }^{59}$.

É inegável que a adequação da coerência do ordenamento e de sua aplicabilidade pode implementar uma série de benefícios sociais. Dentre eles, a segurança jurídica e a igualdade. Logo, no plano teleológico, a coerência é um fim a ser alcançado, porque o intérprete tem o dever de eliminar as antinomias, por exemplo - que seriam contradições graves encontradas no interior do ordenamento jurídico. E isto é uma imposição do

\footnotetext{
${ }^{57}$ COING, Helmut. Op. Cit., p. 200.

${ }^{58}$ Aquilo que permanece no tempo tende a ganhar a confiança das pessoas. Logo, a ordem jurídica duradoura tende a ser mais previsível, uma vez que "se sabe o que esperar". O efeito colateral desta "estagnação" consiste na possibilidade de o direito não vir a dar respostas reais aos problemas sociais. Por isto que os mecanismos de atualização do direito devem existir, apesar de intentarem ser compatíveis com a coerência interna deste direito, e responderem aos reais influxos da sociedade. Assim, o direito estabelece uma "ordem pacificadora", que serve à segurança, mas que pode estar em tensão com a justiça. Enfím, todos os direitos que se mantêm e que se garantem podem ser um desencontro à exigência de justiça. O direito, então, "luta contra si mesmo" e "contra os novos direitos". Nesta "tensão", será importantíssimo estruturar uma coerência, tanto entre as hierarquias externas, com em relação às internas (COING, Helmut., Op. Cit., p. 190191).

${ }^{59}$ COING, Helmut., Op. Cit., p. 194. O autor cita, como exemplos de instituições que intentam manter a segurança jurídica, os registros públicos de documento propriedade, a coisa julgada, o ato jurídico perfeito, entre outros.
} 
Revista Eletrônica de Direito Processual - REDP.

Rio de Janeiro. Ano 12. Volume 19. Número 2. Maio a Agosto de 2018

Periódico Quadrimestral da Pós-Graduação Stricto Sensu em Direito Processual da UERJ

Patrono: José Carlos Barbosa Moreira (in mem.). ISSN 1982-7636. pp. 149-172

www.redp.uerj.br

princípio da igualdade, a ser alcançado tanto em nível de produção normativa, quanto em nível de aplicação do direito posto ${ }^{60}$.

Deve ser ressaltado que a perspectiva teleológica da coerência vê a questão em um plano mais abrangente do que a perspectiva analítica, na medida em que percebe e compreende não aquilo que é, mas muito mais aquilo que deveria ser. Explico: caso um ordenamento democraticamente estabelecido não implementa adequadamente os valores fundamentais do ser humano, como condição para que se desenvolva de modo pleno suas qualidades intelectuais e morais, há uma falha do sistema jurídico, quiçá pela sua incoerência. Daí porque, por exemplo, os postulados normativos são estruturados para corrigir estas idiossincrasias ${ }^{61}$.

Especificamente no que tange aos precedentes, a coerência permite a sua universalização, sendo este último um atributo sine qua non àquele instituto. Afinal, não se mostra legítimo universalizar o que não é coerente. Eis mais uma das finalidades da coerência, ligada ao seu aspecto pragmático.

\section{Coerência no plano pragmático}

Muitas são as manifestações da coerência no plano jurídico como um todo. Em verdade, aqui, pretendemos exemplificar como o sistema jurídico nacional se organizou para evitar incongruências. Devemos perceber que o problema posto não se resume em tratar sobre o direito, mas sim, do direito. Logo, não estamos diante de uma questão epistemológica, mas sim, normativa ${ }^{62}$, de modo que assumimos que a problemática em se pensar um ordenamento jurídico coerente é, em suma, também uma questão prática.

\footnotetext{
60 OTERO, Paulo. Legalidade e Administração Pública: o sentido da vinculação administrativa à juridicidade. Coimbra: Almedina, 2003, p. 727. Ainda que o autor esteja a tratar do tema sob a perspectiva da atuação do administrador público.

${ }^{61}$ ALBUQUERQUE JÚNIOR, Raimundo Parente de. Juridicidade contra legem no processo administrativo. Limites e possibilidades à luz dos postulados da razoabilidade e da proporcionalidade. Porto Alegre: Livraria do Advogado, 2010, p. 31.

${ }^{62}$ Não queremos dizer com isso que o problema da coerência tratará de estudar as normas ou seus significados. Não é, definitivamente, este o objeto da problemática. Ele é normativo porque, no âmago da questão, está um problema de aplicação e de percepção do direito positivo. Assim, a preocupação final consiste em uma intencional realização do direito, a fim de orientar uma paxis.
} 
Revista Eletrônica de Direito Processual - REDP.

Rio de Janeiro. Ano 12. Volume 19. Número 2. Maio a Agosto de 2018

Periódico Quadrimestral da Pós-Graduação Stricto Sensu em Direito Processual da UERJ

Patrono: José Carlos Barbosa Moreira (in mem.). ISSN 1982-7636. pp. 149-172

www.redp.uerj.br

O direito atribui a certas autoridades competência para decidir, seja na esfera administrativa, seja na esfera judicial ${ }^{63}$. Como vimos, reclama-se deste sujeito que interprete o sistema jurídico de modo adequado, integrando eventuais lacunas e justificando sua decisão - Karl Larenz ${ }^{64}$ afirma que, neste momento, há um desenvolvimento do direito que supera a lei. Neste aspecto, tal decisão pode a vir a pautar, no futuro, pontos de vista similares, sendo que o conteúdo da fundamentação pode atuar para além do caso concreto. Assim, no caso, o precedente serviria como "modelo" para as futuras resoluções que se refiram a casos semelhantes. E isto tende a dar coerência a atuação dos tribunais, tornando-se útil à segurança jurídica ${ }^{65}$.

Deve ser destacado, por oportuno, que ao precedente importa o quadro da fundamentação da decisão, e não o dispositivo, o qual se volta ao caso concreto ${ }^{66}$. Não é à toa que, de tanto serem invocados pelas partes e pelas decisões dos tribunais inferiores, acabam por se "incorporar ao direito vigente" 67 . É importante deixar claro que a vinculação se estabelece a partir da norma corretamente interpretada no precedente. No civil law o precedente é normalmente interpretativo. Em verdade, pode realizar uma colmatação de lacunas, implementando a consistência do direito. O nível do precedente está ligado às razões. Assim, "decisão" não se confunde com "precedente”, que, por sua vez, não se confunde com "súmula".

\section{Considerações finais}

Uma das maiores endemias passíveis de serem acometidas ao sistema jurídico (entendido, aqui, como uma totalidade ordenada) consiste na falta de coerência. Retomando o que se disse logo no início da exposição, esta endemia geraria o caos, o que

\footnotetext{
63 Isso já era visto em Kelsen: “[...] a Constituição apenas pode conferir competência para tal a um determinado órgão jurídico (...) só ao próprio órgão legislativo ou a um órgão diferente dele - v.g. ao tribunal que tem de aplicar a lei, ou tão-somente a um tribunal especial - pode ser conferida competência para decidir a questão da constitucionalidade de uma lei." (KELSEN, Hans. Teoria pura do direito. São Paulo: Martins Fontes, 1995, p. 301).

${ }^{64}$ LARENZ, Karl. Metodologia da ciência do direito. Trad. José Lamego. Lisboa: Calouste Gulbenkian, 1997, p. 610.

${ }^{65}$ LARENZ, Karl. Op. Cit., p. 611.

${ }^{66}$ MITIDIERO, Daniel. Precedentes - da persuasão à vinculação. São Paulo: Revista dos Tribunais, 2017, p. 84 e ss.

${ }^{67}$ GERMAN, Oscar Adolf. Präjudizien als Rechtsquelle: eine Studie zu den Methoden der Rechtsfindung. Estocolmo: Almqvist \& Wiksell, 1960, p. 45 e ss.
} 
Revista Eletrônica de Direito Processual - REDP.

Rio de Janeiro. Ano 12. Volume 19. Número 2. Maio a Agosto de 2018

Periódico Quadrimestral da Pós-Graduação Stricto Sensu em Direito Processual da UERJ

Patrono: José Carlos Barbosa Moreira (in mem.). ISSN 1982-7636. pp. 149-172

www.redp.uerj.br

levaria o direito à falência. Sendo assim, a percepção de uma teoria da coerência mostra-se

fundamental. Viu-se, então, em múltiplos planos metodológicos, como ela poderia se processar, concluindo que o sistema deverá evitar toda sorte de antinomias (adquirindo, pois, consistência), bem como deverá fazer sentido (adquirindo, pois, coerência).

Vale dizer que este sistema jurídico deve possui mecanismos de proteção e de eliminação de premissas contraditórias ou incompatíveis. Até porque as normas jurídicas não estão isoladas, mas se inter-relacionando. Sendo assim, um sistema jurídico coerente pressupõe a ausência de antinomias. E seu desafio é compatibilizar e fornecer sentido às múltiplas diferenças evidentemente encontradas no ordenamento normativo. Por isso que a coerência não é condição de validade deste ordenamento, mas sim, condição para sua justiça.

\section{REFERÊNCIAS BIBLIOGRÁFICAS:}

ALBUQUERQUE JÚNIOR, Raimundo Parente de. Juridicidade contra legem no processo administrativo. Limites e possibilidades à luz dos postulados da razoabilidade e da proporcionalidade. Porto Alegre: Livraria do Advogado, 2010.

ALEXY, Robert. Constitucionalismo discursivo. Trad. Luís Afonso Heck. Porto Alegre: Livraria do Advogado, 2015.

ARMINJON, Pierre; NOL'DE, Boris Ėmmanuilovich (baron); WOLFF, Martin. Traité de droit compare. Paris: Librairie Générale de Droit et de Jurisprudence, t. 1, 1950.

ARRUDA, Thais Nunes de. Juízes e casos difíceis. O pragmatismo de Richard Posner e a crítica de Ronald Dworkin. Curitiba: Juruá, 2014.

ATIENZA, Manuel. Las razones del derecho. Teorías de la argumentación jurídica. México: Universidade Autônoma de México, 2005.

BARBOZA, Estefânia Maria de Queiroz. Precedentes judiciais e segurança jurídica fundamentos e possibilidades para a jurisdição constitucional brasileira. São Paulo: Saraiva, 2014.

BOBBIO, Norberto. Teoria da norma jurídica. São Paulo: EDIPRO, 2014. Teoria do ordenamento jurídico. Trad. Ari Marcelo Solon. São Paulo: EDIPRO, 2014.

CRUET, Jean. A vida do direito e a inutilidade das leis. Leme: Edijur, 2003. 
Revista Eletrônica de Direito Processual - REDP.

Rio de Janeiro. Ano 12. Volume 19. Número 2. Maio a Agosto de 2018

Periódico Quadrimestral da Pós-Graduação Stricto Sensu em Direito Processual da UERJ

Patrono: José Carlos Barbosa Moreira (in mem.). ISSN 1982-7636. pp. 149-172

www.redp.uerj.br

CHIASSONI, Pierluiggi. L'indirizzo analítico nella filosofia del diritto. I. Da Benthan a

Kelsen. Torino: Giappichelli Editore, 2009.

COING, Helmut. Elementos fundamentais da filosofia do direito. Porto Alegre: Sérgio

Fabris, 2002.

COMANDUCI, Paolo e GUASTINI, Ricardo. L'analisi del ragionamento giuridico.

Materiali ad uso degli studenti. Torino: Giappichelli, 1989.

DWORKIN, Ronald. Império do direito. Trad. Jefferson Luiz Camargo. São Paulo: Martins Fontes, 1999.

Levando os direitos a sério. São Paulo: Martins Fontes, 2002.

Uma questão de princípio. Trad. Luis Carlos Borges. São Paulo: Martins Fontes, 2000.

ENGISH, Karl. Introdução ao Pensamento Jurídico. Lisboa: Fundação Calouste Gulbekian, 1977.

FERRAZ JÚNIOR, Tércio Sampaio. Introdução ao estudo do direito. Técnica, decisão, dominação. São Paulo: Atlas, 1994.

GEACH, P. T. Razão e argumentação. Trad. Clarissa Vido, Gustavo Coelho, Luis Fellipe Garcia. Porto Alegre: Penso, 2013.

GUEST, Stephen. Ronald Dworkin, jurists: profiles in legal theory. Stanford University Press: Stanford, 1991.

GERMAN, Oscar Adolf. Präjudizien als Rechtsquelle: eine Studie zu den Methoden der Rechtsfindung. Estocolmo: Almqvist \& Wiksell, 1960.

GUASTINI, Riccardo. Interpretación, estado y constituición. Lima: Ara, 2010.

JÈZE, Gaston. Principios generales del derecho administrativo. Buenos Aires: Depalma, v. 3,1982 .

KELSEN, Hans. Teoria pura do direito. São Paulo: Martins Fontes, 1995.

LARENZ, Karl. Metodologia da ciência do direito. Trad. José Lamego. Lisboa: Calouste Gulbenkian, 1997.

LUHMANN, Niklas. El derecho de la sociedad. Trad. Javier Torres Nafarrate. México: Universidade Iberoamericana/Colección Teoria Social, 2005.

LEFEBVRE, Henri. O direito à cidade. São Paulo: Centauro, 2001.

MacCORMICK, Neil. Legal reasoning and legal theory. Oxford: Oxford University Press, 1978. 
Revista Eletrônica de Direito Processual - REDP.

Rio de Janeiro. Ano 12. Volume 19. Número 2. Maio a Agosto de 2018

Periódico Quadrimestral da Pós-Graduação Stricto Sensu em Direito Processual da UERJ

Patrono: José Carlos Barbosa Moreira (in mem.). ISSN 1982-7636. pp. 149-172

www.redp.uerj.br

- Retórica e o Estado de Direito: Uma teoria da argumentação jurídica. Trad.

Conrado Hübner Mendes e Marcos Paulo Veríssimo. Rio de Janeiro: Elsevier, Campus, 2008.

MARTEL, Letícia de Campos Velho. Devido processo legal substantivo - razão absoluta, função e características de aplicabilidade. A linha decisória da Suprema Corte estadunidense. Rio de Janeiro: Lumen Juris, 2005.

MIRANDA, Jorge. Manual de direito constitucional. Coimbra: Coimbra Editora, t. IV, 2000.

MITIDIERO, Daniel. Cortes Superiores e Cortes Supremas: do controle à interpretação, da jurisprudência ao precedente. São Paulo: Revista dos Tribunais, 2014.

Precedentes - da persuasão à vinculação. São Paulo: Revista dos Tribunais, 2017.

NEVES, Antônio Castanheira. Castanheira Neves. A unidade do sistema jurídico: o seu problema e o seu sentido. Boletim da Faculdade de Direito. Estudos em homenagem ao Prof. Doutora J. J. Teixeira Ribeiro. Coimbra: Universidade de Coimbra, número especial, 1979.

OTERO, Paulo. Legalidade e Administração Pública: o sentido da vinculação administrativa à juridicidade. Coimbra: Almedina, 2003.

PECZENIK, Aleksander. On law and reason. Lexington: Springer, 2009.

SAVIGNY, Friedrich Carl Von. Sistema del diritto romano attuale. Trad. Vittorio Scialoja. Torino: Utet (Unione Tipográfico-Editrice Torineze), v. 1, 1888.

SCALIA Antonin. A matter of interpretation. Federal courts and the law. New Jersey: Princenton University Press, 1997.

SKINNER, Quentin. Significado y compreensóin em la história de las ideias. Prismas: Revista de História Intelectual, n. 4, 2000, p. 149-191.

VASCONSELLOS, Fernando Andreoni. Interpretação do direito tributário. Entre a coerência e a consistência. Curitiba: Juruá, 2014.

ZAGREBELSKI, Gustavo. El derecho dúctil. Madrid: Trotta, 2003. 